\title{
CENTRO EXPERIMENTAL DE DIFICULTADES DEL APRENDIZAJE “CEDAP”
}

Este Centro inaugurado hace ya un año, ha venido funcionando regularmente y cubriendo en la medida de lo posible los objetivos propuestos así:

- Como "Aula Remedial" el CEDAP presta servicio directo de diagnóstico, psicoterapia, terapia y educación remedial a los niños del Jardín de la Universidad Surcolombiana con necesidad de ayuda complementaria, y de asistencia a los padres de los mismos.

- Como centro universitario de investigación y experimentación, se han desarrollado en él las prácticas de "Orientación Pedagógica de Pro- blemas de Conducta" (V Semestre Educación Preescolar); se hicieron observaciones sistemáticas y se aplicaron diversas pruebas psicológicas; se hizo seguimiento individual de 15 casos por intermedio de las alumnas de III Semestre de Educación Preescolar en la asignatura Psicologia Evolutiva II" con la orientación de la profesora titular y la asesoría del centro; se asesoraron 8 trabajos de investigación, que sobre aprendizaje, prevención de dificultades y educación remedial realizaron las alumnas de VII Semestre de Educación Preescolar, se orientaron algunos otros trabajos que en el Area del aprendizaje y sus dificulta- 
des realizan diversas personas de la Facultad de Educación y egresados de la misma; se participó directamente en la elaboracion de los proyectos: "Incidencia de la Educación Preescolar en el rendimiento académico de los niños de 1o. y 20 . de básica primaria"; "Desarrollo comunal y familiar en función del niñon preescolar"; "Proyecto de Autoevaluación de la Facultad de Educación". Además se están sistematizando las experiencias acumuladas hasta ahora con el fin de que ellas sirvan para retroalimentar o modificar las prácticas psicopedagógicas $y^{\prime}$ los programas.

-En cuanto a extensión a la comunidad el Centro ha prestado ya innumerables servicios de asesoría y asistencia a la Secretaria de Educación del Departamento en cuanto a capacitación, preparación de eventos y documentos; se ha salido igualmente a varias escuelas y colegios que han solicitado nuestra colaboración en charlas y conferencias con maestros y alumnos; se participó en un curso de capacitación en Lecto-escritura organizado por Aphel; se realizaron seminarios con la Asociación de Egresados en F,du- 
cación Preescolar y con las profesoras del mismo programa; igualmente se realizarán proximamente seminarios de capacitación con profesores y alumnos de los programas de Matemáticas y Lingüistica de la USCO.

Fs de interés absoluto, para el cumplimiento total de los objetivos de una Clínica Psicológica Universitaria como la recientemente inaugurada en el CEDAP, la conformación de un equipo interdisciplinario que tenga capacidad de resolver problemas en las diferentes áreas 0 aspectos que tocan con la conducta y el aprendizaje y sus difi. cul tades. Fsperamos avanzar en este sentido para 1988 .

Nuestro objetivo más inmodiato es el de la ejecución de los proyece. tos antes mencionados y el de una vinculación más efectiva a los demás progranas de la Facultad de Educación (diferentes de Educación Preescolar), programas estos dirigi. dos a profesores de secundaria y de primaria los que sin tardar mucho encontrarán un al to porcentaje de sus alumnos con dificultades de comportamiento y de aprendizaje $y$, a los cuales tendrán que ayudar o dejar sucumbir o desertar. 